\title{
Intestinal Parasitosis
}

\author{
B. Shakya, ${ }^{1}$ D. Bhargava, ${ }^{1}$ S. Shrestha, ${ }^{1}$ B. P. Rijal. ${ }^{2}$ \\ ${ }^{1}$ Department of Microbiology, National Medical College and Teaching Hospital, Birgunj, Parsa, Nepal, ${ }^{2}$ Department of \\ Microbiology, Institute of Medicine, Tribhuvan University Teaching Hospital, Kathmandu, Nepal
}

Correspondence to: Bikash Shakya, Department of Microbiology, National Medical College and Teaching Hospital, Birgunj, Parsa, Nepal. Phone No: 051-532260, 9803276930, Fax: 00977-51-532261

Email:bikashshaky@gmail.com

\begin{abstract}
Introduction: Intestinal parasitosis is highly prevalent among general population and hospital patients in Nepal. The study aimed to assess the prevalence of intestinal parasitosis among patients in a hospital of Nepal.

Methods: A retrospective study was done by analyzing the findings of stool examined from April 2006 to March 2008 at Department of Microbiology of the hospital. $\chi^{2}$-test was used for analytical assessment.

Results: Out of 2221 fecal samples, $20.7 \%$ were positive, the positivity being $23.9 \%$ and $15.8 \%$, respectively in first and second year $(\mathrm{P}<0.05)$. Overall infection rate was nearly equal in male and female (20.2\% vs. $21.2 \%)$. The infection rate was highest among patients of $\geq 60$ years $(25.3 \%)$ followed by those of $<15$ years $(21.2 \%)$ and $15-59$ years $(20.1 \%)(P>0.05)$. Ascaris lumbricoides $(31.8 \%)$ and Entamoeba histolytica $(38.0 \%)$ were the commonest helminth and protozoa, respectively. Other parasites were Hookworm (18.3\%), Hymenolepis nana (2.6\%), Taenia solium (2.6\%), Strongyloides stercoralis (1.3\%) and Giardia lamblia (5.5\%).

Conclusions: Though, the prevalence of intestinal parasitosis among hospital visiting patients is declining, high detection of A. lumbricoides and E. histolytica signifies the need of public awareness regarding latrine use, water source protection from fecal contamination, proper sanitation and hygienic behavior.
\end{abstract}

Keywords: Ascaris lumbricoides, Entamoeba histolytica, intestinal parasites.

\section{Introduction}

Intestinal parasitosis, a major public health problem, particularly in the developing countries, affects 3.5 billion people globally. ${ }^{1}$ Moreover, WHO has estimated that Ascaris lumbricoides, hookworm and Trichuris trichiura infect 1.4 billion, 1.3 billion and 1.0 billion people worldwide, respectively. ${ }^{2}$ The high prevalence rate is attributed to lack of education, lack of latrines, occurrence of diarrhea, lower socio-economic status, inadequate disposal of human excreta and the level of sanitation in households. ${ }^{3}$

In Nepal, the prevalence ranges from $27.0 \%$ to $76.4 \%$ in different studies carried out among general population in different geographical areas ${ }^{47}$; whereas, hospital records in Nepal showed the infection rate of $30.0-40.0 \% .^{4}$ Additionally, a hospital based study conducted by Rai et al (1995) over one decade in Kathmandu illustrated that intestinal parasitosis rate ranged from $29.1-44.2 \%$, with a static prevalence of A. lumbricoides, the most common parasite in Nepal. ${ }^{8}$ Other studies among the patients visiting health care centers in Kathmandu have reported the prevalence rate of $56.0 \%$ and $30.0 \% .^{9-10}$ Whereas, the prevalence rate of $18.9 \%$ has been reported among adult outpatients in a hospital, elsewhere in the world. ${ }^{11}$ In this paper, we report the prevalence of intestinal parasites among patients visiting a medical college at the southern border of Nepal as studied over the two years period (April 2006March 2008). 


\section{Methods}

A retrospective study was done by analyzing the findings of the stool examination carried out from April 2006 to March 2008 at Department of Microbiology in National Medical College and Teaching Hospital, Birgunj, Parsa, Nepal. A total of 2221 stool samples (1251 in the first year and 876 in the second year) submitted for the detection of intestinal parasites was included in the study. All stool samples collected in the wide mouthed, clean, dry, screw capped plastic containers were examined macroscopically and microscopically. The direct smear technique (saline and iodine preparations) was employed and the findings were stratified against the age and sex. Statistical significance was analyzed by using Chi-Square test.

\section{Results}

Out of 2221 fecal samples (1345 in first year and 876 in second year) examined for intestinal parasites during the period, $459(20.7 \%)$ samples were positive (Fig. 1). The positive rate was $23.9 \%$ and $15.8 \%$, respectively in two years $(\mathrm{P}<0.05)$. The overall infection rate was nearly equal in male and female in two years period (20.2\% vs. $21.2 \%$ ) (Fig.1), however, the pattern being quite different in individual years (25.2\% for male and $22.2 \%$ for female during first year while $12.5 \%$ for male and $19.6 \%$ for female in successive year) (Fig. 2). The parasitic infection rate was highest among the patients of 60 years and above (25.3\%), followed by those of less than 15 years $(21.2 \%)$ and those of 15 to 59 years $(20.1 \%)(\mathrm{P}>0.05)$ (Fig. 3). The mixed infection rate was found to be $2.2 \%$ out of total positive samples and $0.5 \%$ out of total samples. In total, 7 types of parasites ( 5 helminths and 2 protozoans) were recovered from the samples. Ascaris lumbricoides (31.8\%) and Entamoeba histolytica (38.0\%) were the commonest helminth and protozoa, respectively. The other parasites found were Hookworm (18.3\%), Hymenolepis nana (2.6\%), Taenia solium (2.6\%), Strongyloides stercoralis (1.3\%) and Giardia lamblia $(5.5 \%)$ (Table 1). Out of total parasites detected, $56.5 \%$ were helminthes and $43.5 \%$ were protozoans (Table 2 ).

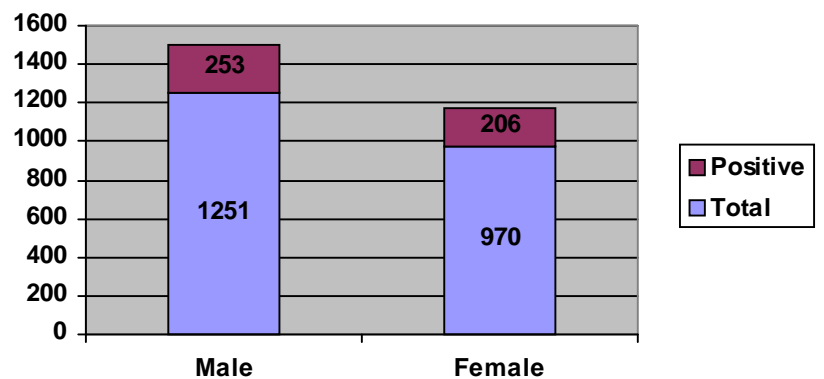

Fig. 1: Distribution of parasitic infection in different genders

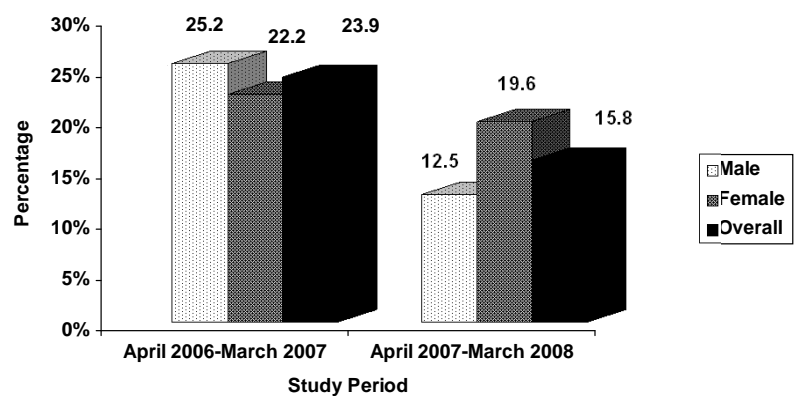

Fig. 2: Gender distribution of intestinal parasitosis in two different years

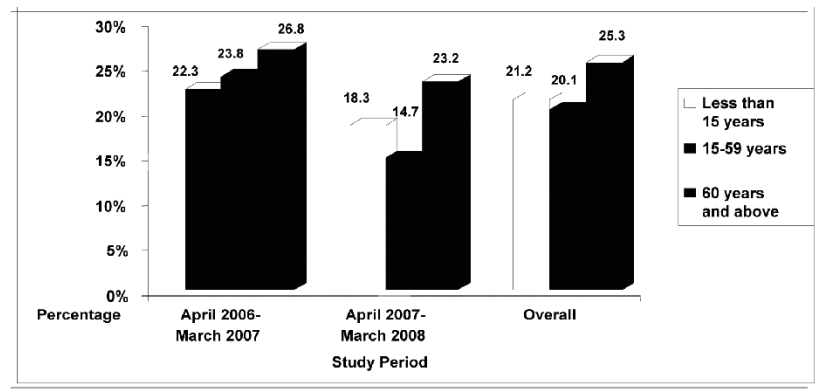

Fig. 3: Age distribution of intestinal parasitosis in different study periods

Table 1: Pattern of parasitic infections among patients

$\begin{array}{ll}\text { Type of infection } & \text { Frequency (\%) } \\ \text { Single parasite } & 449(97.8) \\ \text { Protozoa } & 196(42.7) \\ \text { Helminth } & 253(55.1) \\ \text { Multiple parasite } & 10(2.2) \\ \text { Protozoans } & 3(0.7) \\ \text { Helminthes } & 5(1.1) \\ \text { Protozoans + Helminthes } & 2(0.4) \\ \text { Total } & 459(100)\end{array}$

Table 2: Frequency of intestinal parasites detected

$\begin{array}{ll}\text { Parasites } & \text { Frequency }(\%) \\ \text { A. lumbricoides } & 149(31.8) \\ \text { Hookworm } & 86(18.3) \\ \text { H. nana } & 12(2.6) \\ \text { T. solium } & 12(2.6) \\ \text { S. stercoralis } & 6(1.3) \\ \text { Total helminthes } & 265(56.5) \\ \text { E. histolytica } & 178(38.0) \\ \text { G. lamblia } & 26(5.5) \\ \text { Total protozoans } & 204(43.5) \\ \text { Total parasites } & 469\end{array}$




\section{Discussion}

In the two years period (April 2006 to March 2008), nearly one-fifth of patients seeking parasite detection in their fecal samples were found to carry one or more intestinal parasites, the prevalence rate being higher in the first year and lower in the successive year $(23.9 \%$ vs. $15.8 \%)(\mathrm{P}<0.05)$ (Fig.1). The rate was much lower than that reported earlier among patients in different health care centers of Kathmandu Valley, and that among general population elsewhere in Nepal. ${ }^{4-10}$ However, the significant decline in prevalence rate in the successive year was in agreement with the trend reported by Rai SK (1995) in Tribhuvan University Teaching Hospital, Kathmandu. ${ }^{8}$ The remarkably lower prevalence in the present study as compared to the previous ones and the abating trend of parasitic prevalence may be attributed to the awareness regarding the personal and community hygiene, environmental sanitation, improved socioeconomic status and the regular deworming programme being conducted, particularly for the children etc. Beyond the country, the parasitic prevalence rate has been reported very low in a Thai Hospital $(8.9 \%){ }^{12}$

Both male and female have been found to be equally infected with the parasite, which was in agreement with other studies on general population in Nepal and elsewhere in the world; however, the prevalence rate was higher among male in the first year and lower in the successive year. ${ }^{5,6,13,14}$ This is suggestive of parasitic infection being gender independent as other studies in Nepal and elsewhere have also reported flickering (inconsistent) gender based prevalence. 5, 6, 8, 10, 12 , 15-17

Elderly people (more than 60 years) in the study have been found to suffer higher infection rate as compared to the children and adult. About one-quarter of elderly patients have parasitic infection which is quite lower than that reported earlier by Shakya et al (2006). ${ }^{18}$ This might be attributed to the use of concentration technique for the parasite detection in the later case, which might have increased the parasite detection rate. In contrary, adult patients have been found to have higher parasitic prevalence as compared to elderly and children in similar set ups in Nepal and elsewhere. ${ }^{10,12}$ Similarly, nearly equal infection rate observed among adult and children was also in contrary with the comparatively higher rate reported among the child patients; however it agreed with Rai et al (2000). ${ }^{9,6}$ On the other hand, the prevalence rate observed among the adults was in agreement with the rate reported among adult out patients in similar set up elsewhere in the world. ${ }^{11}$ Similarly, the prevalence rate reported among children was also much lower than that reported in Kanti
Children Hospital, Kathmandu and that among children elsewhere in Nepal, nearly a decade back. ${ }^{6,8,9,19}$ The declining trend may be attributed to regular deworming program conducted during recent years especially in schools and the improved hygienic behavior as mentioned earlier.

The higher helminthic infection rate in the study was in agreement with that among general population in Nepal. ${ }^{6,8}$ This might be due to the presence of more open land, open field defecation and agriculture as the major occupation of the people in the region. A. lumbricoides, reported as the commonest helminth in the study agreed with the study among general population and that among hospital visiting patients in Nepal during a period of ten years and that among patients visiting a Kathmandu based medical care center, recently. ${ }^{5-8,10}$ On the other hand, Uga et al (2004) reported $T$. trichiura as the commonest helminth among patients visiting different medical centers in Kathmandu. ${ }^{9}$

Likewise, E. histolytica reported as the commonest protozoan and the commonest parasite as well in the study was in complete agreement with Rai et al (2007) but it was not in compliance with the similar studies in Nepal and elsewhere. ${ }^{8-10,12}$ Infection with E. histolytica is common in the inhabitants of developing countries; it predominantly affects people with poor socioeconomic conditions, poor hygienic practices, and malnutrition. ${ }^{18}$ The higher infection with $E$. histolytica may be attributed to poor sewerage system in the community, and the fecal contamination of ground water, the ground water being major source of drinking water in the region.

\section{Conclusions}

Though, the overall prevalence of intestinal parasitosis among the hospital visiting patients is declining, the high detection of parasites like A. lumbricoides and $E$. histolytica indicates the high soil contamination with the helminth and high water contamination with the protozoa in the localities around the hospital; thus it signifies the need of public awareness regarding use of latrine, water source protection from fecal contamination, proper sanitation and hygienic behavior along with the continuity to the mass deworming program.

\section{References}

1. World Health Organization. World Health Report 2000. Conquering suffering enriching humanity. Geneva: WHO; 2000.

2. World Health Organization. World Health Report 1996. Conquering suffering enriching humanity. Geneva: 
WHO; 1996.

3. Smith H, Dekaminsky R, Niwas S, Soto R, Jolly P. Prevalence and intensity of infections of Ascaris lumbricoides and Trichuris trichiura and associated socio-demographic variables in four rural Honduran communities. Mem Inst Oswaldo Cruz. 200;96(3): 303-14.

4. Chhetri MK. Parasitic infection in Nepal. Journal of Nepal Medical Association 1997; 35:60-5.

5. Ishiyama S, Rai SK, Ono K, Uga S. Small-scale study on intestinal parasitosis in a remote hilly village in Nepal. Nepal Med Coll J. 2003;5(1):28-30.

6. Rai SK, Matsumura T, Ono K et al. Intestinal parasitosis in an "unknown disease outbreak" hit rural hilly area in western Nepal. Nepal Med Coll J 2000;2:61-4.

7. Rai SK, Nakanishi M, Upadhyay MP, Rai CK, Hirai K, Ohno Y, et al. Effect of intestinal helminth infection on some nutritional parameters among rural villagers in Nepal. Kobe J Med Sci 1998;44(2):91-8.

8. Rai SK, Bajracharya K, Budhathoki S, et al. Status of intestinal parasitosis at TU Teaching Hospital. J Inst Med (Nepal) 1995; 17: 134-42.

9. Uga S, Rai SK, Kimura K, et al. Parasites detected from diarrhoeal stool samples collected in Kathmandu, Nepal. Southeast Asian J Trop Med Public Health 2004;35:19-23.

10. Rai CK, Shrestha A, Shah RDP, Rai SK. Study of intestinal parasitosis among patients visiting health care center in Kathmandu Valley. J Nepal Assoc Med Lab Sci 2007;8:33-6.

11. Kyrönseppä H, Pettersson T. The occurrence of human intestinal parasites in Finland. Scand J Infect Dis 1976;8(3):199-202.

12. Nuchprayoon S, Siriyasatien P, Kraivichian K, Porksakorn C, Nuchprayoon I. Prevalence of parasitic infections among Thai patients at the King Chulalongkorn Memorial Hospital, Bangkok, Thailand. J Med Assoc Thai 2002;85(1 1):S415-23.

13. Sinniah B, Rajeswar B. Economic status associated with intestinal nematode infections. In: Collected papers on the control of soil transmitted helminthes. Tokyo: The Asian Parasite Control Organization; 1998. p. 71-7. (Collected papers on the control of soil transmitted helminthes; vol 7).

14. Sayyari AA, Imanzadeh F, Bagheri Yazdi SA, Karami H,
Yaghoobi M. Prevalence of intestinal parasitic infections in the Islamic Republic of Iran. East Mediterr Health J. 2005;11(3):377-83.

15. Oliveira MC, Silva CV, Costa-Cruz JM. Intestinal parasites and commensals among individuals from a landless camping in the rural area of Uberlândia, Minas Gerais, Brazil. Rev Inst Med Trop Sao Paulo 2003 ;45(3):173-6.

16. Feng $\mathrm{Z}, \mathrm{Xu} \mathrm{L}$, Lin J. Analysis of the change of soil transmitted nematode infections in the three country/ city in Fujian Province. In: Collected papers on the control of soil transmitted helminthes.: The Asian Parasite Control Organization; 2001. p. 90-6. (Collected papers on the control of soil transmitted helminthes; vol 7).

17. Rajeswari B, Sinniah B, Hussein H. Socio-economic factors associated with intestinal parasites among children living in Gombak, Malaysia. Asia Pac J Public Health. 1994;7(1):21-5.

18. Shakya B, Rai SK, Singh A, Shrestha A. Intestinal parasitosis among the elderly people in Kathmandu Valley. Nepal Med Coll J 2006;8:243-7.

19. Rai K, Sherchand JB, Bhatta DR. Study of enteropathogens and its predisposing factors in gastroenteritis suspected children attending Kanti Children Hospital, Kathmandu, Nepal. J Nepal assoc Med Lab Sciences 2004;6:48-53. 